\title{
Heterogeneous lithosphere in Central Tibet: insights from the Mantle Xenoliths
}

YU YANG ${ }^{12}$, RAINER ABART ${ }^{1}$, XIAOSONG YANG ${ }^{2}$, THEO NTAFLOS ${ }^{1}$,

${ }^{1}$ Department of Lithospheric Research, University of Vienna, Vienna, Austria

${ }^{2}$ State Key Laboratory of Earthquake Dynamics, Institute of Geology, China Earthquake Administration, Beijing, China

The tectonic evolution of the Tibetan Plateau is discussed controversially. Two major hypotheses, one postulating a northward subduction of the Indian plate complemented by concomitant southward subduction of the Eurasian plate and another suggesting a unidirectional northward subduction of the Indian plate, have been proposed.

We present new data from peridotite mantle xenoliths, which were exhumed by Eocene volcanism in the Qiangtang terrane. The systematic lateral and radial variation of the petrological, geochemical and microstructural signatures of the xenoliths reflect a heterogeneous structure of the lithospheric mantle below central Tibet. The uppermost lithospheric mantle is refractory and exhibits AG-type olivine fabric with a point maximum of the [010] axes normal to the foliation plane and a girdle distribution of the [100] and the [001] axes in the foliation plane. In contrast, the lower part was re-fertilized and displays a different fabric characterized by dominant activation of the $[001](010)$ slip system. We infer that the fabric of lower part of the lithospheric mantle was transformed from AG-type into B-type fabric during melt-related deformation associated with re-fertilization by asthenosphere upwelling. Convective removal of the lowermost lithosphere is the most likely scenario driving this re-fertilization in the lower sections of the lithospheric mantle. At the same time, the refractory 'ghost lithosphere' residing in shallower regions beneath the Qiangtang terrane preserved the earlier AG-type fabric. It may thus represent a residual subcontinental lithospheric mantle, which remained in the current lithospheric mantle. The vertical dichotomy of the mantle produces multiple seismic interferences, which correspond well with deep seismic observations and corroborate the model of a single northward subduction of the Indian plate. 